im Hinblick auf ihre Unfruchtbarkeit als Bastarte angesprochen. $V$. spectabilis aber entwickelt reichsamige, wohl ausgebildete Kapseln, auch kommt sie in solcher Menge vor, dass man sich schwer entschliessen könnte, sie für ein Kreuzungsprodukt zu halten, zumal $V$. odorata L., welche den Merkmalen der Pflanze nach jedenfalls zu den muthmasslichen Eltern gehören würde, in ihrer Nähe nicht zu finden war. Auch wäre $V$. odorata $\times$ hirta $=V$. permixta Jord. die einzige Combination, welche den Merkmalen der $V$. spectabilis entspräche. Diese aber nähert sich durch die langgestielten Sommerblätter mehr der $V$. austriaca A. et J. Kerner, und wäre also gar ein Tripelbastart anzunehmen, was noch mehr mit dem häufigen Vorkommen im Widerspruch stände.

Nach alledem dürfte es wohl gerechtfertigt sein, dieses schön $\theta$ Veilchen als neue Art anzusehen.

Dasselbe wurde, wie bereits erwähnt, von mir bisher nur bei Gloggnitz, hier aber sehr häufig gefunden. Es wäre jedoch sehr leicht möglich, dass es auch an anderen Orten wächst, zu welcher Annahme mich namentlich der Umstand verleitet, dass ich öfter in Herbarien ähnliche Violen unter allen möglichen Namen vorfand. Da dieselben aber meist mangelhaft gesammelt und noch schlechter getrocknet waren, so wage ich es nicht, dieselben bei der grossen Schwierigkeit, welche die Bestimmung getrockneter Veilchen überhaupt hat, als mit meiner Species identisch hinzustellen. Jedenfalls wird es eine dankbare Aufgabe für den Pflanzensammler sein, dem Vorkommen derselben weiter nachzuspüren.

\title{
Einiges zur Kenntniss der Rostpilze.
}

\section{Von Wilhelm Voss.}

Es gibt nicht viele Familien in der Classe der Pilze, die in den letzteren Jahren mit so grosser Vorliebe studirt wurden, als jene der Uredineen. Die Folge davon war zunächst die Entdeckung zahlreicher, früher unbekannter oder nicht unterschiedener Arten, das Auffinden neuer Nährpflanzen und die Aufklärung interessanter biologischer Erscheinungen. Es wurden unsere Kenntnisse nach diesen Richtungen bedeutend erweitert, jedoch nicht zum Abschlusse gebracht; darüber belehrten mich auf meinen Excursionen zwei Funde, worüber ich kurz berichten will.

\section{Puccinia (Pucciniopsis) carniolica nov. spec.}

Krain ist bekanntlich reich an eigenthümlichen Arten aus der Familie der Umbelliferen. Auf einer derselben, Peucedanum Schottii Bess., gelang es mir einen Rostpilz aufzufinden, der mit obigen Namen bezeichnet werden könnte. Am Wege unter den Schlossfelsen bei 
Veldes in Oberkrain, wo diese Dolde in grösserer Menge wächst, an welcher Stelle sie durch Valentin Plemel (wie Herbarstücke bezeugen) aufgefunden wurde, beobachtete ich in der zweiten Hälfte des September, theils an den Blättern, theils auf dem Stengel derselben Aecidien in verschiedener Entwicklung und die Polster der Teleutosporen.

Die recht kleinen Aecidienbecher stehen auf der Unterseite der Blätter, einzeln oder zu wenigen $(2-5)$ in Gruppen; hin und wieder auch einzeln an den Blattstielen. Die umgebende Blattsubstanz ist gelblich gefärbt; sonstige Veränderungen, wie Krümmungen u. dgl. werden nicht hervorgerufen. Die Mündung der Becher ist weisslich und etwas geschlitzt, das Innere schön orange gefärbt. Die Sporen sind kugelig, elliptisch oder auch polyedrisch, glatt und orange. Die Zellen der Pseudoperidie hingegen farblos, wesshalb leere Aecidien weiss erscheinen. Den Aecidien gehen wenige Spermogonien voran. Biologisch von Interesse ist das späte Auftreten der Aecidien, die ich noch im October neu gebildet vorfand.

Bald nachdem die ersten Aecidien abgewelkt, bilden sich die Teleutosporen; von Uredo konnte nichts wahrgenommen werden. Ihre Polster findet man an den Blättern und den Blattstielen sehr häufig in unmittelbarer Nähe der leeren Aecidien. Auch diese bewirken keinerlei Deformation der befallenen Theile. Die von der Epidermis bedeckten Sporenlager sind schwarz und etwas glänzend. Die Gestalt der Sporen sehr verschieden; es finden sich keil- und keulenförmige neben oblongen oder ganz unregelmässig geformten. Auch einzellige (Mesosporen) sind beigemengt. Die obere Sporenzelle ist bei den beiden ersten Formen am breitesten, so dass der Sporenkörper allmälig in den Stiel übergeht. In der Mitte ist derselbe nur wenig eingeschnürt; sein Scheitel abgestumpft oder gewölbt, manchmal auch zugespitzt und stärker verdickt. Das glatte Epispor, sowie der Sporeninhalt ist braun gefärbt in der Weise, dass die Farbe von der Basis gegen den Scheitel an Tiefe zunimmt. Die hyalinen, oder im oberen Theile lichtbraun gefärbten, meist fest anhaftenden Stielzellen sind in der Regel kürzer, selten so lang als die Spore. menfassen.

Diese Verhältnisse liessen sich in folgende Diagnose zusam-

\section{Fung. hymeniiferus. Aecidium Peucedani m.}

Aecid. pseudoperidiis plerumque hypophyllis, sparsis, minutis, ore albo dilacerato, disco luteo. Sporis plus minusve globosis, ellipsoideis vel polygonis, episporio levi, intus luteis; $20 \mathrm{~mm}$. diam. vel 24-26 long., 15 lat.

\section{Fung. teleutosporiferus.}

$P$. acervulis pulvinatus, hypophyllis, etiam in petiolo longitudinaliter dispositis, epidermide tectis (semper?), nigris. - Sporis irregularibus, aut cuneatis, aut clavatis, aut oblongis, aut polyedris, 
vertice truncatis, rotundatis vel apiculatis, incrassatis, medio paullulo constrictis, basi in pedicello angustatis, episporio levi, fuscis; 49-53 long. (sine pedicello), 20-24 lat. (loc. sup.).

In Peucedani Schottii Bess. foliis et petiolis vivis, in eodem tempore. - Carniolia: Veldes, in monte cui ar $x$ superstructa est. Septemb.

Diese Art gehört der fehlenden Uredo wegen zur Section Pucciniopsis Schröt. und wäre der $P$. Bunii und $P$. Falcariae (siehe Rabenh. Krypt.-Flora, 2. Aufl., 1. Bd. [bearb. von Dr. G. Winter], pag. 197) anzuschliessen. Von diesen beiden Arten ist $P$. carniolica verschieden: 1. durch das Aecidium, welches bei $P$. Bunii in zahlreichen Bechern am Stengel auftritt und mannigfaltige Verkrümmungen verursacht, bei $P$. Falcariae hingen über die ganze Blattfläche der Nährpflanze gleichmässig vertheilt und sonst auch anders gebaut ist; 2. durch die Teleutosporen. Zu einer der übrigen, auf Umbellaten vorkommenden Arten, kann sie der Aecidien und der fehlenden Uredo wegen, meiner Ansicht nach, nicht leicht gebracht werden; übrigens unterscheidet sie sich von $P$. Oreoselini und $P$. bullata, die gleichfalls auf Peucedanum-Arten auftreten, durch die Form der Wintersporen.

Dr. J. Schroeter gibt in Cohn's Beiträgen zur Biologie der Pflanzen (3. Band, pag. 81) eine Uebersichtstabelle der auf euroäischen Umbelliferen vorkommenden Puccinien. In dieselbe würde $P$. carniolica in folgender Weise einzureihen sein.

Sect. Pucciniopsis. Spermogonien, Aecidien und Teleutosporen bekannt. Uredobildung unterdrückt.

a) Membran der Teleutospore ganz glatt.

$\alpha$. Spore am Scheitel kaum merklich und nur an kleiner Stelle (Keimstelle) verdickt.

$\beta$. Spore am Scheitel deutlich und ziemlich stark ver-

dickt. $P$. carniolica n. sp.

$P$. Falcariae Pers.

b) Membran der Teleutosporen durch feine Eindrücke netzförmig gezeichnet.

c) Membran der Teleutospore grobhöckerig P. Bunii (DC.)

P. Smyrnii Corda.

\section{Uromyces (Euuromyces) Cytisi (DC.) Schroet.}

Dieselben Felsen des Veldeser Schlossberges, worauf Peucedanum Schottii wächst, werden auch von zahlreichen Stauden des Cytisus hirsutus L. bedeckt. In der zweiten Hälfte des Monates Juli beobachtete ich an den Blättern dieser Pflanze Spermogonien nebst Aecidien und die schon früher bekannt gewesene Uredo. Als ich im October dieselbe Localität wieder besuchte, hatten sich auch die Teleutosporenlager gebildet.

Die Aecidienbecher finden sich gewöhnlich auf der Unterseite der Blätter in elliptischen oder rundlichen Gruppen, ziemlich dicht beisammen. Ihr Vorhandensein verräth sich an der Oberseite der 


\section{$2 \mathrm{BHL}$ Biodiversity Heritage Library}

Voss, Wilhelm. 1885. "Einiges zur Kenntniss der Rostpilze." Oesterreichische botanische Zeitschrift 35(12), 420-423.

View This Item Online: https://www.biodiversitylibrary.org/item/35443

Permalink: https://www.biodiversitylibrary.org/partpdf/246842

\section{Holding Institution}

University Library, University of Illinois Urbana Champaign

\section{Sponsored by}

University of Illinois Urbana-Champaign

\section{Copyright \& Reuse}

Copyright Status: NOT_IN_COPYRIGHT

This document was created from content at the Biodiversity Heritage Library, the world's largest open access digital library for biodiversity literature and archives. Visit BHL at https://www.biodiversitylibrary.org. 